\title{
A Case of Slowly Progressive Purulent Pericarditis in Elderly Healthy Woman
}

\author{
Eitaro Kodani*, Takeshi Tadera, Chikao Ibuki, Yoshiki Kusama and Hirotsugu Atarashi \\ Department of Internal Medicine and Cardiology, Nippon Medical School Tama-Nagayama Hospital, Tokyo, Japan \\ *Corresponding author: Eitaro Kodani, MD, Department of Internal Medicine and Cardiology, Nippon Medical School Tama-Nagayama Hospital, 1-7-1 Nagayama, \\ Tama-shi, Tokyo 206-8512, Japan, Tel: +81-42-371-2111; E-mail: kodani@nms.ac.jp
}

Received date: Feb 11, 2014, Accepted date: Feb 25, 2014, Published date: Mar 3, 2014

Copyright: (c) 2014 Kodani E, et al. This is an open-access article distributed under the terms of the Creative Commons Attribution License, which permits unrestricted use, distribution, and reproduction in any medium, provided the original author and source are credited.

\begin{abstract}
A 67-year-old woman was admitted with dyspnea. The cheat X-ray showed marked cardiomegaly and the echocardiography revealed diffuse massive pericardial effusion but no finding of vegetation on valves. Clinical sign

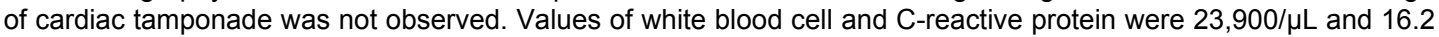
$\mathrm{mg} / \mathrm{dL}$, respectively. Immediately, pericardiocentesis was performed. Pericardial effusion was yellowish purulent exudate and Streptococcus pneumoniae was detected in culture. The early pericardial drainage and the effective doses of intravenous antibiotics and $\mathrm{y}$-globulin were successful for the treatment of this bacterial pericarditis, and no more surgical procedure was needed. Neither recurrence of inflammation nor constrictive pericarditis was developed after discontinuation of antibiotics during the follow-up period for over three years at the outpatient clinic. In this case, an infection route was unknown since pneumonia, empyema, or other focus of infection was not found. Although she had an upper respiratory infection one year prior to this pericarditis, their association was unclear. She was previously healthy and was not a compromised host. This case is thought to be rare bacterial pericarditis with slow progression in the recent antibiotic era.
\end{abstract}

Keywords: Bacterial pericarditis; Streptococcus pneumonia; Pericardiocentesis

\section{Introduction}

Acute purulent pericarditis is rare as the cause of acute pericarditis. Recently, it has become extremely rare because of the development of antibiotics. Sodeman et al. reported in 1958 [1] that purulent pericarditis was $16 \%$ in 240 cases with pericarditis. In contrast, Permanter-Miralda et al. reported in 1985 [2] that purulent pericarditis was only $2 \%$ in 231 cases with acute pericarditis between 1977 and 1983. Klacsmann et al. [3] compared the causes of bacterial pericarditis between two generations before 1943, in which antibiotics had not yet developed, and after 1943. Pneumococcus was the most common (51\%) infecting organism followed by Staphylococcus (19\%), Streptococcus (10\%), and gram-negative bacilli (5\%) before 1943 , whereas the frequency of infection due to gram-negative aerobic bacilli increased (39\%) followed by Staphylococcus (22\%), Streptococcus (13\%), and Pneumococcus (9\%) after 1943.

At this time, we had experienced a case of purulent pericarditis caused by Streptococcus pneumoniae with slow progression in a 67- year-old woman. This case is thought to be rare in the recent antibiotic era. Therefore, we herein report a case of slowly progressive purulent pericarditis in elderly healthy woman and its successful treatments.

\section{Case Report}

A 67-year-old woman suffered from common upper respiratory infection one year before present illness. She had no diabetes or history of obvious disease. She treated it with over-the-counter drugs but was feeling general fatigue even after improved. About one year later, she was admitted to the general hospital with dyspnea. The blood examinations showed severe anemia (hemoglobin $[\mathrm{Hb}] 5.9 \mathrm{~g} / \mathrm{dL}$ ) and she received blood transfusion immediately. At the hospital, echocardiography was performed and massive pericardial effusion was found. Then, she was transferred to our hospital two days later. On admission, her body temperature was $36.8^{\circ} \mathrm{C}$, blood pressure was $110 / 66 \mathrm{mmHg}$, and pulse rate was regular at $120 / \mathrm{min}$. No pericardial friction rub, heart murmur, or chest rale was heard. Mild dilatation of carotid vein was observed. The blood examinations on admission were shown in Table 1, indicating iron deficiency anemia (Hb 7.4 g/dL, Fe 5 $\mu \mathrm{g} / \mathrm{dL}$, and ferritin $13 \mathrm{ng} / \mathrm{mL}$ ).

\begin{tabular}{|l|l|l|l|l|l|}
\hline \multicolumn{2}{|l|}{ Blood examinations on admission } & AST & $37 \mathrm{IU} / \mathrm{L}$ & UA & $5.5 \mathrm{mg} / \mathrm{dL}$ \\
\hline WBC & $23,900 / \mathrm{mL}$ & ALT & $26 \mathrm{IU} / \mathrm{L}$ & $\mathrm{Na}$ & $139 \mathrm{mEq} / \mathrm{L}$ \\
\hline Stab & $3.0 \%$ & LDH & $281 \mathrm{IU} / \mathrm{L}$ & $\mathrm{K}$ & $4.6 \mathrm{mEq} / \mathrm{L}$ \\
\hline Seg & $95.0 \%$ & gGTP & $48 \mathrm{IU} / \mathrm{L}$ & Cl & $103 \mathrm{mEq} / \mathrm{L}$ \\
\hline Mono & $2.0 \%$ & CPK & $24 \mathrm{IU} / \mathrm{L}$ & Ca & $8.2 \mathrm{mg} / \mathrm{dL}$ \\
\hline RBC & $419 \times 104 / \mu \mathrm{L}$ & T-Bil & $2.3 \mathrm{mg} / \mathrm{dL}$ & BS & $146 \mathrm{mg} / \mathrm{dL}$ \\
\hline Hb & $7.4 \mathrm{~g} / \mathrm{dL}$ & & & \\
\hline
\end{tabular}


Page 2 of 4

\begin{tabular}{|l|l|l|l|l|l|}
\hline $\mathrm{Ht}$ & $27.2 \%$ & T-Cho & $120 \mathrm{mg} / \mathrm{dL}$ & CRP & $16.2 \mathrm{mg} / \mathrm{dL}$ \\
\hline $\mathrm{MCV}$ & $64.9 \%$ & TG & $89 \mathrm{mg} / \mathrm{dL}$ & ESR & $42 \mathrm{~mm} / \mathrm{h}$ \\
\hline $\mathrm{MCH}$ & $17.7 \mathrm{pg}$ & TP & $6.7 \mathrm{~g} / \mathrm{dL}$ & BNP & $552 \mathrm{pg} / \mathrm{mL}$ \\
\hline $\mathrm{MCHC}$ & $27.2 \%$ & Alb & $2.9 \mathrm{~g} / \mathrm{dL}$ & Fe & $5 \mathrm{mg} / \mathrm{dL}$ \\
\hline $\mathrm{Plt}$ & $51.5 \times 104 / \mathrm{\mu L}$ & BUN & $34.1 \mathrm{mg} / \mathrm{dL}$ & UIBC & $277 \mathrm{mg} / \mathrm{dL}$ \\
\hline & & Cr & $0.6 \mathrm{mg} / \mathrm{dL}$ & Ferritin & $13 \mathrm{ng} / \mathrm{mL}$ \\
\hline & & & Fib & $459 \mathrm{mg} / \mathrm{dL}$ \\
\hline
\end{tabular}

Table 1: Blood examinations on admission

The serum white blood cell (WBC) count was $23,900 / \mu \mathrm{L}$ and the fractions showed left shift of neutrophils (stab cell 3.0\%, segmented cell $95.0 \%$, and monocyte $2.0 \%$ ). C-reactive protein (CRP) was 16.2 $\mathrm{mg} / \mathrm{dL}$ and erythrocyte sedimentation rate (ESR) was $42 \mathrm{~mm} / \mathrm{h}$, whereas transaminases and creatinin phosphokinase were within normal range. The chest $\mathrm{X}$-ray showed marked cardiomegaly (cardiothoracic ratio [CTR] 74\%) with slight dull finding in bilateral costophrenic angles, but without inflammatory or congestive sign in lungs (Figure 1).

The electrocardiogram (ECG) showed sinus tachycardia with heart rate of $149 / \mathrm{min}$, low voltage in all leads, slight elevation of ST segments in I, II, V5, and V6 leads, and depression of PR segments in I, II, and aVF leads (Figure 2).

The echocardiography showed diffuse pericardial effusion about 20 $\mathrm{mm}$ in apical four-chamber view (Figure 3), but left ventricular systolic function was normal and no vegetation was found on the valves.

The patient immediately underwent pericardiocentesis via apical route by using aspiration catheter. The pericardial effusion was yellowish purulent exudate including huge amount of neutrophils. Cultures of both pericardial effusion and arterial blood were positive for Streptococcus pneumoniae. The finding of cytology showed no atypical cell (Class II). We diagnosed as purulent pericarditis and started intravenous injections of antibiotics (panipenem/batemiprom [PAPM/BP] $1 \mathrm{~g} /$ day) and $\gamma$-globulin $(5 \mathrm{~g} /$ day).

The clinical courses of treatments and inflammatory signs on blood examinations were shown in Figure 4.

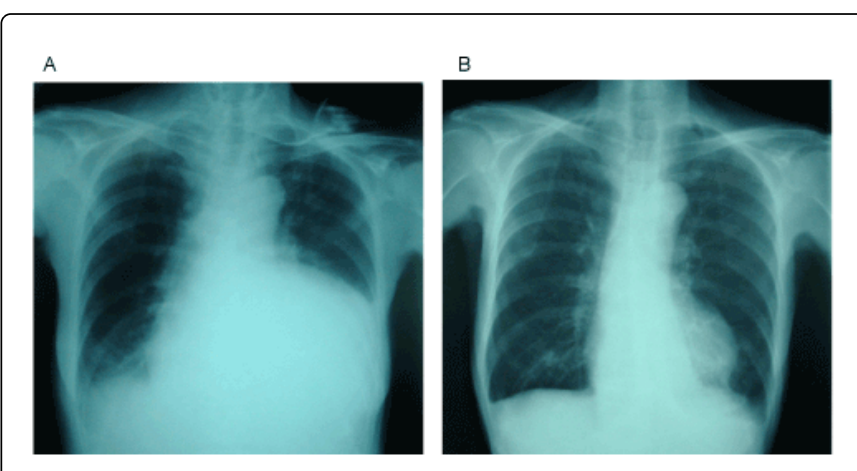

Figure 1: Chest X-ray films on admission (A) and at discharge (B).

A: Cardiothoracic ratio (CTR) was $74 \%$; B: CTR was $52 \%$.

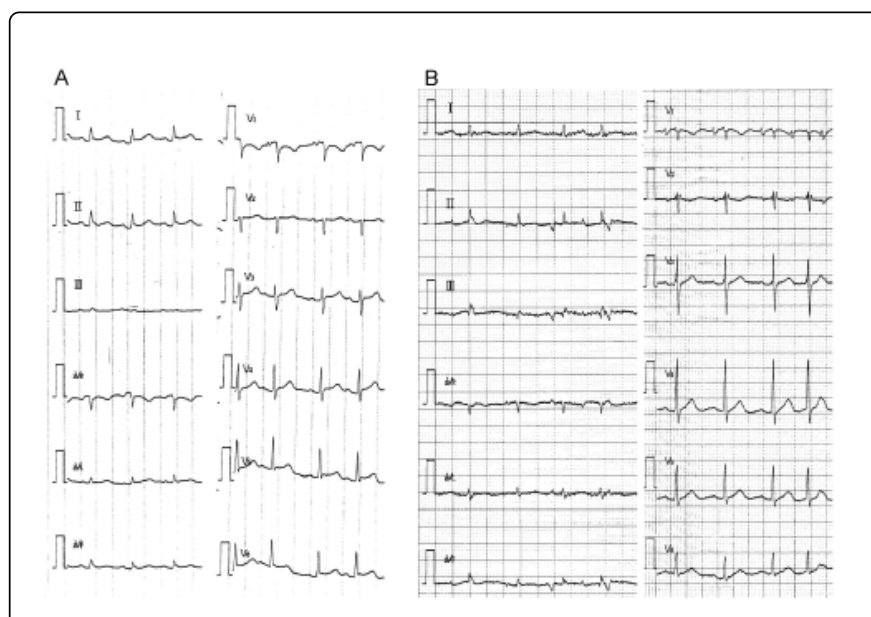

Figure 2: Electrocardiograms on admission (A) and at discharge (B).

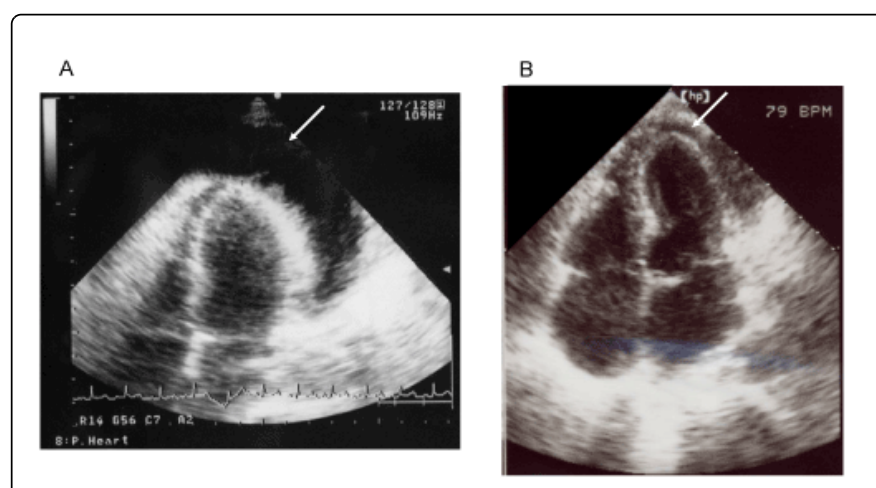

Figure 3: Echocardiography in apical four-chamber view on admission (A) and at discharge (B).

Arrow pointers show pericardial effusion.

Open squares show the values of WBC $(/ \mu \mathrm{L})$. Closed circles show the values of CRP $(\mathrm{mg} / \mathrm{dL})$. Open circles show the values of ESR $(\mathrm{mm} / \mathrm{h})$.

Although a $680 \mathrm{ml}$ of pericardial effusion was removed by the first pericardiocentesis, fever of $37-38^{\circ} \mathrm{C}$ and inflammatory signs, i.e. elevation of WBC and CRP, continued for two weeks. Since the 
echocardiography and the chest computed tomography revealed that modest pleural and pericardial effusion still existed, thoracentesis on the 12th day and the second pericardiocetesis on the 28th day were performed. A $750 \mathrm{ml}$ of pleural effusion and an additional $240 \mathrm{ml}$ of pericardial effusion could be evacuated. After these invasive techniques, body temperature normalized and inflammatory signs improved. The values of WBC and CRP decreased to $6,200 / \mu \mathrm{L}$ and 1.4 $\mathrm{mg} / \mathrm{dL}$ on the 43rd day, respectively. The tricuspid regurgitation on the echocardiography and peripheral edema were observed temporally during this period. Diuretics were administered appropriately but catecholamine was not needed. In addition, the value of $\mathrm{Hb}$ recovered to $11.3 \mathrm{~g} / \mathrm{dL}$ by an administration of sodium ferrous citrate and no more blood transfusion was needed. The fecal occult blood test was always negative through the hospitalization and no malignancy in gastrointestinal tracts was detected. Therefore, the anemia in this case was thought to be the result of chronic inflammation. The chest magnetic resonance imaging on the 49th day revealed thickening and edema of pericardium, which were compatible findings as bacterial pericarditis (Figure 5).

As a result of these managements, her general condition dramatically improved and the CTR decreased to $52 \%$ on the chest Xray (Figure 1B). Administration route of antibiotics was altered before discharge from intravenous to oral (faropenem [FRPM] $600 \mathrm{mg} /$ day and levofloxacin [LVFX] $300 \mathrm{mg} /$ day). Although slight inflammatory signs on the blood examinations, ectopic and premature atrial beats on the ECG (Figure 2B), and a small amount of pericardial effusion on the echocardiography (Figure $3 \mathrm{~B}$ ) still remained, she finally left the hospital on the 81st day without any additional surgical procedure. The oral antibiotics were able to discontinue at four months after discharge at the outpatient clinic. Neither recurrence of inflammation nor constrictive pericarditis was observed after discontinuation of antibiotics during the follow-up period for over three years. The latest values of WBC and CRP were $4,300 / \mu \mathrm{L}$ and $0.18 \mathrm{mg} / \mathrm{dL}$, respectively.

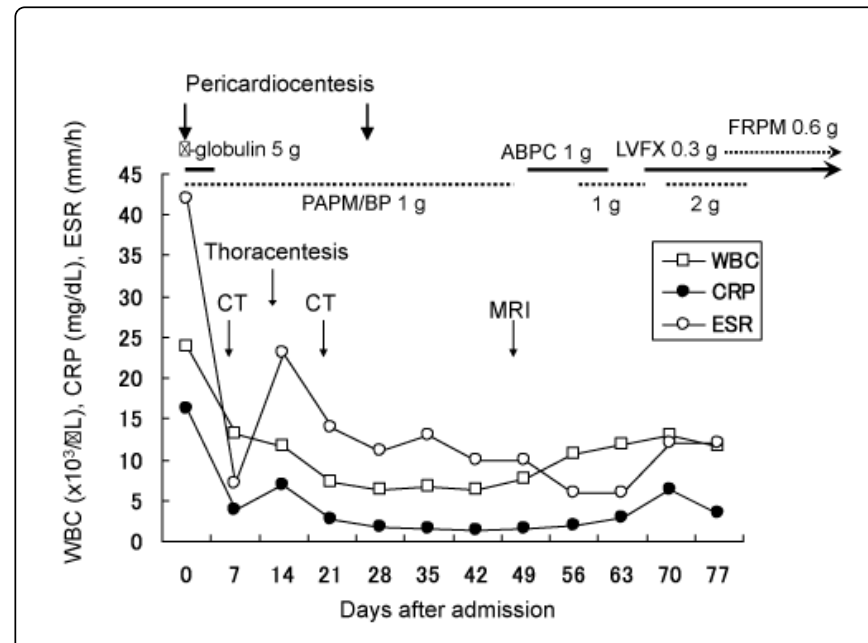

Figure 4: Clinical courses of treatments and inflammatory signs on blood examinations.

WBC: White blood cell; CRP: C-reactive protein; ESR: Erythrocyte sedimentation rate; CT: Computed tomography, MRI: Magnetic resonance imaging; PAPM/MP: Panipenem/batamiprom; ABPC: Ampicillin; LVFX: Levofloxacin; FRPM: Faropenem

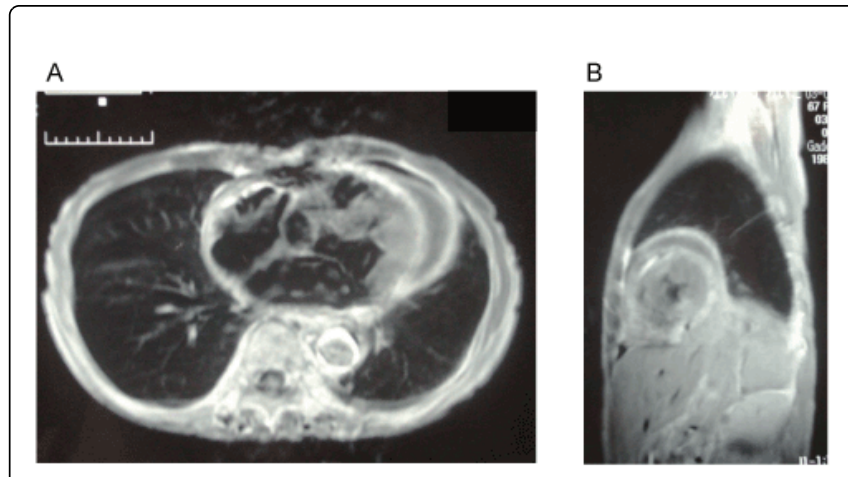

Figure 5: Chest magnetic resonance imaging with gadolinium enhancement in horizontal view (A) and longitudinal view (B).

\section{Discussion}

Purulent pericarditis and cardiac tamponade are known to be major complications of bacterial pericarditis. In the review in 2005 [4], purulent pericarditis is the most serious manifestation of bacterial pericarditis. Usually, it is an acute and fulminant illness with pyrexia. In addition, purulent pericarditis is always fetal if untreated. The mortality in even treated patients is $40 \%$, and death is mostly due to cardiac tamponade, systemic toxicity, cardiac decompensation, or constriction. The incidence of bacterial pericarditis is higher in compromised hosts such as patients with acquired immune deficiency syndrome (AIDS) than in the general population.

Although Streptococcus pneumoniae would not be rare as the cause of infective pericarditis, which was the secondary predominant microorganism responsible for purulent pericarditis following Staphylococcus aureus in a recent review [5], there, were some atypical findings in the present case compared with previous reports. First, the patient did not have severe general condition. Despite the value of WBC was $23,900 / \mu \mathrm{L}$ and pathogenic bacteria was detected in both pericardial effusion and arterial blood cultures, her body temperature was not high on admission. Although nocturnal low-grade fever of 37$38^{\circ} \mathrm{C}$ was observed in the first two weeks after admission, it was not severe in contrast with typical pericarditis or sepsis. We could not explain clearly why the reaction of temperature for inflammation was unremarkable, but she did not notice her illness for long time consequently. In addition, although massive pericardial effusion was found on the echocardiography, no cardiac tamponade was diagnosed clinically since there was no finding of either electrical alternance or paradoxical pulse. This finding indicated that the pericarditis had developed very slowly. Second, the source of infection was unclear. In some previous manuscripts [2,6-12], most patients with bacterial pericarditis could be found the possible source of infections. SagristaSauleda and colleagues, whose group had published the series of a lot of manuscripts focused on the pericarditis for over two decades, reported that the empyema and pneumonia remained common predisposing conditions [9]. However, no pneumonia, empyema, or other focus of infection was found in the present case. Keersmaekers et al. [13] reported a very similar case of primary bacterial pericarditis in 36-year-old man. Immune insufficiency state should be considered in young patients [14] but the antibody of human immunodeficiency virus (HIV) was negative in their report. Unfortunately, the antibody of HIV was not checked in our case, but she was previously healthy 
and was not a compromised host evaluated from her past history and examinations on admission. Although she had an upper respiratory infection one year prior to this pericarditis, their association was unclear. Third, no additional surgical procedure was needed. We performed pericardiocentesis at bedside and evacuated pericardial effusion as much as possible. Then, we started to administer antibiotics and $\gamma$-globulin immediately after admission. Although the second pericardiocentesis was necessary for complete drainage of pericardial effusion, the early pericardiocetesis and the effective doses of antibiotics were useful for the treatment of purulent pericarditis. Usually, an additional surgical treatment is required to remove pericardial effusion completely or to prevent constrictive pericarditis $[6,15,16]$. Indeed, the patient in a similar report by Keersmaekers et al. [13] underwent partial pericardiectomy because cardiac tamponade was developed later. In addition, we did not choose the administration of thrombolytic agent into the pericardial space, because the effect of the thrombolytic therapy was still controversial [17-19].

Finally, there was no evidence of recurrence or constrictive pericarditis during the follow-up period for over three years after discontinuation of antibiotics at outpatient clinic. Even in a similar successful case report [20], the follow-up period was only about one year. Although the treatment with pericardial drainage and antibiotics for this patient was not so special, our managements would be appropriate, resulting in being successful without surgical procedure.

The present case would teach general practitioners that patients with common cold might have any severe cardiac disease with atypical clinical manifestations. We believe that the information of the present case would be useful for daily clinical practice.

\section{References}

1. Sodeman WA, Smith RH (1958) A reevaluation of the diagnostic criteria for acute pericarditis. Am J Med Sci 235: 672-676 passim.

2. Permanyer-Miralda G, Sagristá-Sauleda J, Soler-Soler J (1985) Primary acute pericardial disease: a prospective series of 231 consecutive patients. Am J Cardiol 56: 623-630.

3. Klacsmann PG, Bulkley BH, Hutchins GM (1977) The changed spectrum of purulent pericarditis: an 86 year autopsy experience in 200 patients. Am J Med 63: 666-673.

4. Pankuweit S, Ristic AD, Seferovic PM, Maisch B (2005) Bacterial pericarditis: diagnosis and management. Am J Cardiovasc Drugs 5: 103-112.
5. Parikh SV, Memon N, Echols M, Shah J, McGuire DK, et al. (2009) Purulent pericarditis: report of 2 cases and review of the literature. Medicine (Baltimore) 88: 52-65.

6. Majid AA, Omar A (1991) Diagnosis and management of purulent pericarditis. Experience with pericardiectomy. J Thorac Cardiovasc Surg 102: 413-417.

7. Goodman LJ (2000) Purulent Pericarditis. Curr Treat Options Cardiovasc Med 2: 343-350.

8. Schoen SP, Zimmermann TF, Boscheri A, Schmeisser A, Strasser RH (2005) [Bacterial pericarditis]. Dtsch Med Wochenschr 130: 2198-2202.

9. Sagristà-Sauleda J, Barrabés JA, Permanyer-Miralda G, Soler-Soler J (1993) Purulent pericarditis: review of a 20-year experience in a general hospital. J Am Coll Cardiol 22: 1661-1665.

10. Russell-Taylor M (2000) Bacterial pneumonias: management and complication. Paediatr Respir Rev 1: 14-20.

11. Latyshev Y, Mathew A, Jacobson JM, Sturm E (2013) Purulent pericarditis caused by Haemophilus parainfluenzae. Tex Heart Inst J 40: 608-611.

12. Tokuyasu H, Saitoh Y, Harada T, Touge H, Kawasaki Y, et al. (2009) Purulent pericarditis caused by the Streptococcus milleri group: a case report and review of the literature. Intern Med 48: 1073-1078.

13. Keersmaekers T, Elshot SR, Sergeant PT (2002) Primary bacterial pericarditis. Acta Cardiol 57: 387-389.

14. Gundelly P, Thornton A, Greenberg RN, McCormick M, Myint T (2014) Rhodococcus equi Pericarditis in a Patient Living with HIV/AIDS. J Int Assoc Provid AIDS Care .

15. Troughton RW, Asher CR, Klein AL (2004) Pericarditis. Lancet 363: 717-727.

16. Morgan RJ, Stephenson LW, Woolf PK, Edie RN, Edmunds LH Jr (1983) Surgical treatment of purulent pericarditis in children. J Thorac Cardiovasc Surg 85: 527-531.

17. Juneja R, Kothari SS, Saxena A, Sharma R, Joshi A (1999) Intrapericardial streptokinase in purulent pericarditis. Arch Dis Child 80: 275-277.

18. Bridgman PG (2001) Failure of intrapericardial streptokinase in purulent pericarditis. Intensive Care Med 27: 942.

19. Augustin P, Desmard M, Mordant P, Lasocki S, Maury JM, et al. (2011) Clinical review: intrapericardial fibrinolysis in management of purulent pericarditis. Crit Care 15: 220.

20. Rallidis LS, Thomaidis KP, Vlasseros IN, Xydas TA, Papasteriadis EG (1997) Successful treatment of staphylococcal pericarditis with early catheter drainage and antibiotics. Acta Cardiol 52: 437-443. 